\title{
Mario Pagliaro's Scientific Achievements in Chemistry and Education
}

\author{
Michele Rossi
}

Received: 3 April 2013 / Accepted: 3 April 2013 / Published online: 9 May 2013

(C) Springer Science+Business Media Dordrecht 2013

\section{Outlook}

Mario Pagliaro (Palermo, 1969) is a chemistry and energy scholar based in Palermo, Sicily, at Italy's National Research Council (the CNR) where he leads a research group whose activity focuses on the development of functional materials for a variety of uses, including catalysis and photovoltaics, and operates at the boundaries of chemistry and materials science.

Dr Pagliaro's research achievements are reflected in over 80 highly cited research papers published in some 35 different chemistry, energy and environment, materials science, archaeology and science methodology journals covering a similarly broad field of activities.

$\mathrm{He}$ is a highly cited researcher with over 2,000 citations and with an Hirsch "h" citation index of 22, as of early January 2013 (Google Scholar). He has also authored or coauthored 15 books, including best-selling texts on glycerol, functionalized silicas, nanochemistry and solar energy.

In 2011, along with Graham Hutchings, he edited the highly cited Catalysis Science and Technology themed issue "Heterogeneous Catalysis for Fine Chemicals".

Dr Pagliaro regularly organizes conferences and gives courses, seminars and tutorials on the topics of his research. He has chaired the 10th "FIGIPAS Meeting in Inorganic Chemistry" held in Palermo on July 2009.

He co-chairs the "SuNEC Sun New Energy Conference" and the "FineCat Symposium on heterogeneous catalysis for fine chemicals", a series of high-quality scientific meetings

M. Rossi ( $\triangle)$

Dipartimento di Chimica Inorganica, Metallorganica

e Analitica, Università degli Studi di Milano,

via Venezian 21, 20133 Milano MI, Italy

e-mail: michele.rossi@unimi.it held annually in Sicily established by his team, respectively, in 2011 and in 2012.

In 2008, along with University of Palermo's chemistry professor Leonardo Palmisano, Pagliaro has co-founded Sicily's R Photovoltaics Research Pole, a lively joint research and educational unit active in solar energy, a field today showing a renaissance both in Italy and on a global scale.

In 2005 he was appointed "Maître de conférences associé" at Montpellier's Ecole Nationale Superieure de Chimie. In 2012 he a gave an invited lecture on glycerol chemistry at the 22nd Canadian Symposium on Catalysis, following the 2010 keynote lecture at the 8th Eurofedlipid Congress in Munich, and the 2008 "John van Geuns" Lecture at the University of Amsterdam.

Today he is a frequently invited speaker at international conferences and at foreign universities.

\section{Research}

Following his early years of research on polysaccharides oxidation carried out in the Netherlands with Dr Arjan E. J. de Nooy, Dr Pagliaro has been active in the field of sol-gel materials since 1996, when he joined as a PhD student the Lab of David Avnir in Jerusalem, Israel. Back in Sicily at Italy's CNR, in 1999 he started work with research chemist Rosaria Ciriminna.

Together, they conceived and synthesized several new functional silicates that have found application as functional materials as sensors, catalysts and protective coatings. In parallel, they started to study new chemical routes to convert glycerine into value added products.

The early Pagliaro's activity in sol-gel science and technology was devoted to catalysis. The first chemically 
entrapped organocatalyst in a sol-gel $\mathrm{SiO}_{2}$ matrix for sugars selective oxidation in water was described with D. Avnir et al. Chem. Commun. 1441 (2000).

The idea soon led to the design of related entrapped organocatalyst nitroxyl radicals for the the oxidation of alcohols to aldehydes and ketones, with C. Bolm and R. Ciriminna, in Adv. Synth. Catal. 344, 159 (2002) and a new one-pot concept in heterogeneous catalysis for fine chemicals through coupling of two consecutive reaction for the conversion of cheap olefins into valued diols reported with R. Ciriminna et al. in Org. Biomol. Chem. 3, 2389 (2005).

Ciriminna and Pagliaro's studies on heterogeneous oxidation catalysis then led to the development of an highly selective aerobic oxidation catalyst in liquid phase thanks to the entrapment of the Ru-based TPAP in organoalkoxysilane derived sol-gel materials reported in Chem. Eur. J. 9, 5067 (2003).

The study above initiated a voluminous activity as the catalyst proved to be a true "off-the-shelf" catalytic material suitable for conversion under different conditions. Pagliaro's numerous works with Lisboa's Polytechnic Laura M. Ilharco are considered the key reference papers in this domain, and one should mention the seminal work in Chem. Mater. 17, 6686 (2005).

Also in this context, one should also mention the paper published with S. Campestrini in Tetrahedron Lett. 45, 7283 (2004) describing for the first time the use of hydrogen peroxide for alcohol oxidation promoted by TPAP thanks to its entrapment in a leach-proof ORMOSIL matrix.

Their studies on heterogenous catalysis soon extended to supercritical $\mathrm{CO}_{2}$, an environmentally friendly solvent. A relevant paper in this field published with R. Ciriminna and S. Campestrini in Adv. Funct. Mater. 15, 846 (2005), describes the dynamic nature of sol-gel entrapped metal catalysts.

In the same field of research, with J. Moreau and S. Campestrini, Pagliaro was first to describe in Chem. Eur. J. 12,5220 (2006) the SILC (supported ionic liquid catalysis) approach to heterogenous catalysis with silica-entrapped ionic liquids doped with a catalyst.

Input in theoretical studies has been instrumental in his studies on sol-gel doped materials. The physical, chemical and morphology effects on performance of these materials are described in a widely cited trilogy of articles written with R. Ciriminna and G. Palmisano: J. Phys. Chem. 110, 1976 (2006); Chem. Soc. Rev. 36, 932 (2007); and in Chem. Record 10, 17 (2010).

With E. Le Bourhis he was the first to report the organic modification effects on ORMOSIL thin film mechanical properties in Langmuir 22, 11158 (2006).
Yet another major sub-field initiated by D. Pagliaro and his colleagues was the development of optical, non invasive sol-gel sensors for $\mathrm{O}_{2}$ detection based on fluorinated ORMOSIL. The first demonstration of this concept was published with F. V. Bright in Anal. Chem. 77, 2670 (2005).

Many useful sensors using fluorinated sol-gel materials followed soon, and his review with R. Ciriminna in J. Mater. Chem. 15, 4975 (2005) got the cover of the journal and is today a highly cited paper in the field. The same journal hosts another widely cited paper reviewing the science and technology of silica-based hybrid coatings in J. Mater. Chem. 19, 3116 (2009).

Pagliaro's and Ciriminna's work on ORMOSIL catalysts, eventually led, in 2008, to the launch of a series of new commercial catalysts later trademarked SiliaCat by SiliCycle, Inc., a company leading the advanced field of functionalized silica gels.

Between 2007 and 2012, thus, Pagliaro, Béland and their co-workers, respectively, in Italy and Canada published some 20 research papers, first addressing Silia Cat TEMPO, a selective oxidation catalyst, and then the new multipotent Silia Cat $\operatorname{Pd}(0)$ and Silia Cat $\operatorname{Pt}(0)$ nanocatalysts.

The latter catalysts are multipotent as they can be successfully used in reactions as important as C-C coupling as first reported in Catal. Sci. Technol. 1, 736 (2011), or in the fully selective, cis-only hydrogenation of vegetable oils reported in Org. Proc. Res. Devel. 16, 1307 (2012); and in the hydrosilylation of alkenes as recently shown in ACS Sustainable Chem. Engineer. 1, 249 (2013).

This and other related seminal work was featured on the cover of journals like ChemCatChem, Catalysis Science \& Technology and Advanced Synthesis \& Catalysis.

In the field of glycerol's new chemistry, one should first mention the direct, one-pot oxidation of glycerol to mesoxalic acid with organocatalyst TEMPO reported with R. Ciriminna in Adv. Synth Catal. 345, 383 (2003)

The subsequent year, along with M. Rossi and G. Palmisano, he reported the first electrochemical oxidation of glycerol to DHA (di-hydroxyacetone, a valued fine chemical) in Tetrahedron Lett. 45, 6381 (2004).

A major achievement describing the use of raw glyerol streams for the production of green cement additives was then published with M. Rossi in ChemSusChem 1, 809 (2008). This discovery was readily transferred to industry originating production of commercial additives and consumption of thousands of tones of glycerin.

Dr Pagliaro's most cited paper is "From glycerol to valueadded products", published in collaboration with M. Rossi in Angew. Chem. Int. Ed. 46, 4434 (2007) considered by many as the paper that coalesced global interest in new glycerol's chemistry, a by-product of biodiesel production. 
With G. Palmisano and R. Ciriminna in Canadian J. Chem. 87, 673 (2009) they were the first to report the synthesis of nano-sized metal nanoparticles doped with organic molecules.

The novel concept of electrochemically induced sol-gel polycondensation for the deposition of an electrocatalytic film, developed together with G. Palmisano, and then use it for waste-free electrochemical oxidation of alcohols in water was first described in in Adv. Synth. Catal. 348, 2033 (2006).

With M. L. Ferrer and G. Palmisano he has developed self-assembled titania-sepiolite based nanocomposites for water decontamination through photocatalysis, in J. Mater. Chem. 19, 2070, (2009).

Synthetic photocatalysis will be of relevance for $21 \mathrm{st}$ century organic synthesis, and Pagliaro covered the topic in a highly cited report with L. Palmisano and V. Augugliaro, Chem. Commun. 3425 (2007).

Phthalocyanines are widely used today in the chemical industry. The first demonstration of the use of such compounds in the context of doped sol-gel materials was for the preparation of photocatalytic silica-titania thin films, a paper published with G. Palmisano in J. Phys. Chem. 112, 2667 (2008).

Along with Sicily's Superinterndency of the Sea archaeologist S. Tusa, Dr Pagliaro identified the origin of Roman ingots discovered in Sicily's sea, a finding reported in Oxford J. Archaeol. 27, 315 (2008).

In the same context of nautical arhaeology he codeveloped a method to protect the underwater camera at Pantelleria Cala Gadir site with archaeologists P. Selvaggio and S. Tusa, in J. Nautical Archaeol. 38, 417 (2009).

His paper with G. Palmisano and R. Ciriminna on flexile solar cells in ChemSusChem 1, 880 (2008) inaugurated their research in the field of solar energy, and is today the most cited publication in this now booming sector of research.

The feature article on solar hydrogen as fuel of the near future written with leading researcher A. G. Konstandopoulos, in Energy Environ. Sci. 3, 279 (2010) is one of the most frequently cited papers in the field.

Along with R. Ciriminna and PhD student M. Sciortino, Pagliaro has developed new catalytic sol-gel capsules for polyurethane foam formation described in Silicon 3, 77 (2011) [1]. The complex fragrance microencapsulation in silica and organosilica capsules described in ChemPlusChem 77, 536 (2012) opens the route to solid perfumes to be formulated in water.

In this field, the review article on sol-gel microencapsulation published in Chem. Rev. 353, 677 (2011) is considered the key reference in this emerging domain of contemporary chemical research.

\section{Scientific Writing}

Dr Pagliaro has been often cited for his excellence in writing and teaching. He has authored or co-authored 15 books, 11 of which are devoted to his research topics.

The list includes the 2 editions of the bestselling volume 'The Future of Glycerol' written with M. Rossi (RSC Publishing, 2008 and 2010), 'Nano-Age' (Wiley-VCH, 2010), a comprehensive volume on chemistry-enabled nanotechnology; and 'Clean by Light Irradiation', on titania-based photocatalysis, written with L. Palmisano and V. Augugliaro (RSC Publishing, 2010).

His book 'Silica-Based Materials for Advanced Chemical Applications' (RSC Publishing, 2009), was reviewed in SILICON [2] and in Angew. Chem. Int. Ed. 48, 8404 (2009) as being "of great interest for researchers from different scientific communities in academia and industry". His volume "Solar Hydrogen" (RSC Publishing, 2012) was coauthored with the "Descartes Prize" Laureate Athanasios Konstandopoulos.

His textbook on solar energy written with G. Palmisano and R. Ciriminna, 'Flexible Solar Cells' (Wiley-VCH, 2008), is considered instrumental in spreading the word on solar energy flexible technologies. In 2010 the book was translated in Chinese by Shanghai Jiao Tong University Press.

Most recently, he started authoring his books in e-book format and one should mention his digital volume "Glycerol: The Platform Biochemical of the Chemical Industry" (Simplicissimus Book Farm, 2013).

\section{Teaching and Mentoring}

Between 2005 and 2007 he has jointly mentored the doctorate in chemical engineering of G. Palmisano. He was the mentor of the doctorate in sustainable technologies of Marzia Sciortino (2012) and Giovanni Palmisano (2009) both of which were given their doctorate cum laude.

In 2008 he also co-mentored with Venice's University P. Barbante the masters degree of Foscarina Selvaggio Boccaccin, whose work led to the identification of the origin of precious lead ingots of Roman era.

Dr Pagliaro has over 1,000 hours of teaching experience. He currently leads the educational activities of the ClimAbita Foundation in Sicily. Between 2009 and early 2012, Dr Pagliaro has taught new energy technologies at Sicily's PV Research Pole within the the "Solar Master" of the Pole he co-founded in 2008.

From 1999 through 2003 he has trained quality and environmental management managers and young graduates first 
at the "Quality College del CNR", an educational center he established in 1999 at Palermo's CNR, and then also at Italy's School of Public Administration (SSPA).

Overall, he and his associate researchers have demonstrated through their educational efforts, the ability to attract in Sicily bright people from Italy and abroad bridging the long way between scientific education and the creation of real socio-economic value.

\section{Public Outreach}

Since 2004 Dr Pagliaro organizes in Palermo the now prestigious "Marcello Carapezza Seminar", an informal meeting open to the public aimed at promoting public awareness (and understanding) of culture.

Entitled to the memory of Sicily's great geochemist Marcello Carapezza, the seminar reasons are explained in an elegant science methodology paper published by Pagliaro in 2007 entitled "“'Of sea urchins, volcanoes, earthquakes... and engagement": The lives of Marcello Carapezza and Alberto Monroy as a source of inspiration in facing the threats and the opportunities of Italy's university system", Sci. Context 20, 679 (2007).

The seminar was inaugurated in 2004 by economist Francesco Giavazzi, followed by leading Italy's sociologist Giuseppe De Rita, by epistemologist authority Jean Marc Lévy-Leblond in 2007 and by economist Loretta Napoleoni in 2008. In 2011 the seminar hosted by Italy's Parliament was given by the former and current Palermo's mayor Leoluca Orlando.

\section{Summary}

Looking back at when I first met Mario at a 2002 conference of Italy's Chemical Society in Sardinia, I am astonished from all we have achieved together in the subsequent years.

Our common work on glycerol's new chemistry ranges from catalytic electrochemical oxidation to DHA to usage of crude glycerin as a concrete additive. Our book on glycerin, apparently appreciated by many of our colleaugues worlwide, has recently gone through its 2 nd largely expanded edition

Mario is now actively pursuing research in many other specific fields, and so do I. Our friendship remains firm and deep. I wish Mario many fruitful and happy years to continue his scientific and educational activity.

\section{References}

1. Sciortino M, Alonzo G, Ciriminna R, Pagliaro M (2011) SILICON $3(2): 77-83$

2. Clarson SJ (2011) SILICON 3(3):105-107

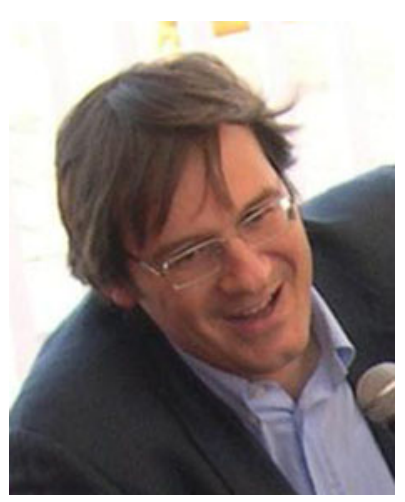

Michele Rossi was chair of inorganic chemistry at the University of Milan until 2010 when he retired as dean of the Science Faculty. His research, documented in more than 150 papers and several patents, is focused on metal-based catalysis and has led to important results in the activation of small molecules for catalytic applications and to the discovery of nitrogen fixation. 